\title{
Adjustment of brood size and androgen levels in a teleost species with exclusive male parental care
}

\author{
Albert F.H. Ros ${ }^{\mathrm{a}, *}$, Teresa Fagundes ${ }^{\mathrm{a}, 1}$, Rui F. Oliveira ${ }^{\mathrm{a}, \mathrm{b}, 1}$ \\ ${ }^{a}$ Unidade de Investigação em Eco-Etologia, Instituto Superior de Psicologia Aplicada \\ ${ }^{\mathrm{b}}$ Champalimaud Neuroscience Programme, Instituto Gulbenkian de Ciência, Portugal
}

\section{A R T I C L E I N F O}

\section{Article history:}

Received 5 March 2008

Initial acceptance 27 June 2008

Final acceptance 16 March 2009

Available online $\mathrm{xxx}$

MS. number: 08-00148R

\section{Keywords:}

11-ketotestosterone

Blenniidae

brood size manipulation

intersexual selection

male quality

peacock blenny

Salaria pavo

testosterone
In maximizing reproductive success, individuals face a trade-off between parental care for their current offspring and investing in androgen-dependent sexual traits to produce further offspring. It has thus been proposed that parental effort would suppress androgen levels. Here, we studied parental effort by manipulating brood size in the peacock blenny, Salaria pavo, a littoral fish species in which males show long periods of paternal care. We focused on the effects of brood size on female spawning rate (measured as number of eggs received in the nest by focal males) and androgen levels. We found a positive linear relationship between brood size and the number of eggs received subsequently. Accordingly, spawning rate increased for males with experimentally enlarged broods while it decreased for males in which brood size was reduced. However, over a longer time interval, brood sizes of both treatments returned to the nonmanipulated brood size, suggesting an effect of additional factors such as male quality. Brood size did not show the expected negative relationship with levels of testosterone and 11-ketotestosterone. On the contrary, testosterone levels were positively correlated with brood size. However, in agreement with the prediction, changes in the level of parental care by manipulation of brood size showed an inverse relationship with testosterone levels. As with brood size, given time, testosterone levels tended to return to nonmanipulated levels. Such changes suggest that males adjust their brood size to an individual value through androgen modulation of courtship or other traits influencing female spawning rate.

(c) 2009 The Association for the Study of Animal Behaviour. Published by Elsevier Ltd. All rights reserved.
Animals are expected to invest in their brood so as to maximize their remaining lifetime reproductive success (Williams 1966; Trivers 1972; Sargent \& Gross 1986). Because parental effort in the form of providing care and protection for offspring is both time and energy consuming, it will reduce resources available for growth and survival and thereby result in a trade-off between current and future reproduction (Clutton-Brock 1991; Stearns 1992; Deerenberg \& Overkamp 1999). Therefore, to maximize lifetime reproductive success, selection should favour mechanisms that adjust parental effort to the reproductive value of the current brood, for example via parental assessment of the number or age of the offspring and the chance of brood loss from predation (Carlisle 1982; Lessells 1993; Magnhagen \& Vestergaard 1993). Such adjustment of parental effort to the reproductive value of the offspring has been well documented in vertebrates (e.g. Lessells 1993; Vélez et al. 2002). Brood size may also be adjusted to parental

\footnotetext{
* Correspondence and present address: A. Ros, Department of Biology, University of Neuchâtel, Emile-Argand, 11, 2009 Neuchâtel, Switzerland.

E-mail address: albert.ros@unine.ch (A.F.H. Ros).

1 T. Fagundes and R. F. Oliveira are at the Unidade de Investigação em Eco-Etologia, Instituto Superior de Psicologia Aplicada, Rua Jardim do Tabaco 34, 1149-041 Lisboa, Portugal.
}

quality via investment in sexual behaviour or via brood reduction (Clutton-Brock 1991). There is still little knowledge about the proximate mechanisms of brood size regulation (Ziegler 2000). Here we investigate such mechanisms in a teleost fish with exclusive male parental care, the peacock blenny, Salaria pavo.

Because of their wide range of effects on reproductive physiology and behaviour, androgens have been commonly studied to analyse the proximate mechanisms underlying life history trade-offs (Wingfield et al. 1990; Ketterson et al. 1996). In many vertebrates including teleost fishes, androgens facilitate competitive behaviours that are typically displayed in sexual competition, and androgen levels have been found to correlate negatively with parental effort (Wingfield et al. 1990; Ziegler 2000; Oliveira 2005). This interaction between androgens and parental effort has been studied experimentally by manipulating androgen levels (Trichogaster trichopterus: Kramer 1972; Lepomis macrochirus: Kindler et al. 1991; Neogobius melanostomus: Murphy \& Stacey 2002; Gasterosteus aculeatus: Páll et al. 2002b; Parablennius parvicornis: Ros et al. 2004), or by manipulating parental effort (L. macrochirus: Magee \& Neff 2006). Contrary to expectation, experimentally elevated androgen levels did not reduce parental care in these studies. However, an experimental reduction in parental effort via brood size reduction (see Coleman et al. 1985 for the relationship between 
brood size manipulation and parental effort) did result in a significant increase in androgen levels in comparison with control males (Magee \& Neff 2006). Thus, parental effort might modulate androgen levels and thereby the extent to which animals are active in sexual competition (reviewed in Hirschenhauser \& Oliveira 2006).

In blennies, males defend nests in a hard substrate to which they attract females to spawn. Nest-holding males provide uniparental care to the eggs until they hatch, and this care consists of agonistic nest defence behaviours and some specialized care behaviours such as fanning, cleaning the nest and removal of infected eggs (Almada \& Santos 1995; Kraak 1996). Blenniid females prefer to spawn in nests with males that care for many eggs (Kraak 1996; Fagundes et al. 2007). Thus it is beneficial for males to have large broods. However, nest-holders in the peacock blenny are often seen to reject courting females while most nests are only partially filled with eggs (Almada et al. 1995). This suggests that caring for a large brood is costly. Large successful broods require more parental effort such as fanning behaviour (see Oliveira et al. 2000; Karino \& Arai 2006). Successfully breeding males also attract small males that try to 'steal' fertilizations or eggs, and this would increase the need to defend the nest with territorial behaviour (Oliveira et al. 2002; Gonçalves et al. 2003). Furthermore, males of the peacock blenny continuously receive eggs from many females and thus their broods are not sequential but rather composed of overlapping batches of eggs. Therefore, during the reproductive period nest-holders are found almost exclusively in their nest, which curtails their opportunity to forage (Almada et al.1994; Gonçalves \& Almada 1998), and results in a decrease in their body condition (Gonçalves \& Almada 1997). Consequently, defence and care for larger broods is costly and thus the brood size that a male may sire successfully is expected to depend on his quality.

The aim of this study was to investigate mechanisms of brood size regulation in the peacock blenny. We used the following approaches.

(1) A database from individually tagged territorial males sampled along an intertidal transect was examined for correlations between morphological characteristics and changes in brood size of nest-holders. Here we expected to find a positive relationship between male morphological characteristics and brood size, and between brood size and the number of eggs the nest-holder receives subsequently (Magnhagen \& Vestergaard 1993; Fagundes et al. 2007).

(2) Brood size was manipulated experimentally to test its effect on subsequent egg number received by the nest-holder. If females base their choice to spawn only on the number of eggs present in the nest, enlarged broods should remain large, while reduced broods should remain small in comparison to nonmanipulated broods. If females spawn independently of the number of eggs in the nest, for example by mate choice for characteristics of the nestholder or the nest site, or when males regulate the number of eggs in their nest by changing the level of mating behaviour, the number of eggs in the nest should return to the premanipulated brood size.

(3) Blood samples were drawn from the manipulated males to check for a relationship between androgen levels (11-ketotestosterone and testosterone) and brood size. High androgen levels were expected to be incompatible with providing elevated levels of parental care, and thus males with a large or enlarged brood were expected to have lower androgen levels than males with a small or reduced brood.

\section{METHODS}

The study was carried out on an intertidal sand flat in the Ria Formosa Natural Park (Ramsar RS212) on an island, Culatra (36 $59^{\prime}$
$\mathrm{N}, 7^{\circ} 51^{\prime} \mathrm{W}$ ), Algarve, Portugal (for a detailed description of the area see Almada et al. 1994). The local fishermen cultivate clams on the intertidal area of the island and border their clam fields with artificial materials such as bricks, tiles, sand sacks and stone debris. This has created artificial reefs providing shelter and nesting sites for marine life. Peacock blenny males, which normally breed in rocky coasts, have populated these reefs where their nests can be found highly aggregated in cavities in the bricks (Almada et al. 1994). The breeding season of the peacock blenny lasts from the end of April to the beginning of September.

\section{Correlates of Brood Size}

As part of a long-term longitudinal study on the life histories and alternative reproductive tactics in the peacock blenny, a transect consisting of an isolated row of 80 bricks $(55 \mathrm{~m})$ on the intertidal flat was sampled from 2002 to 2006 at monthly intervals outside the breeding season and every other week during the breeding season. During low tide, blennies were extracted from brick holes by shaking the bricks. All individuals captured in the transect that were larger than $5.2 \mathrm{~cm}$ total length were individually marked with passive transponders (passive integrated transponder tag; ID100A, Trovan, Aalten, The Netherlands; $11 \times 2.1 \mathrm{~mm}$ ). Passive transponders were inserted through a small incision in the abdominal cavity in animals that were anaesthetized with MS-222 (tricaine methanesulphonate; Pharmaq Ltd, Oslo, Norway, dilution 1:10 000 sea water), and wounds were closed using medical grade adhesive glue. After recovery from anaesthesia the marked fish were released at the site of capture. The identity of marked fish could be obtained in a noninvasive manner by holding the fish close to a portable reader (LID-500, Trovan).

For the current analysis, we used only data of nest-holders. Males were classified as nest-holders if they expressed secondary sexual characters (i.e. a conspicuous head crest and an anal gland) and were found with eggs in their nests. During the breeding season we visited the population every other week during low tide. As part of these regular observations, we collected the following data: (1) standard length ( $\pm 1 \mathrm{~mm})$; (2) the relative size of the head crest, as head height/body size $( \pm 1 \mathrm{~mm})$; (3) body weight, measured using a Pesola spring scale $( \pm 0.5 \mathrm{~g})$; (4) the number of eggs in each nest, calculated by multiplying the area covered with eggs in each nest by the average number of eggs per area, estimated a priori from a subset of nests ( 80 eggs $\mathrm{cm}^{2}$, Gonçalves et al. 2002); and (5) the egg development stage, classified according to a scale of three categories based on colour and visual signs of embryo development: 1 = orange or reddish eggs with no embryo visible (1-3 days old); 2 = brownish eggs with embryo in early stages of development (3-6 days old); 3 = greyish eggs with embryo clearly visible (6-10 days old).

To characterize the changes in reproductive activity over the breeding season, the number of eggs of all nests in the transect were summed over 2-week intervals and the interval values were averaged over the years. To detect which parameters might influence the brood size of males, we calculated Pearson correlations on data collected during June, the peak of the reproductive season (Oliveira et al. 1999; Fagundes et al. 2007).

\section{Brood Size Manipulation}

During the breeding season of 2006 we carried out an experiment to study the effects of a brood size enlargement or reduction on the reproductive fitness of the nest-holder. The result of this brood size manipulation was measured by following the change in egg number in the nest over a 2-week interval and comparing this result with the change in egg numbers during a sham treatment 
period of equal duration. At the start of a sham treatment period ('sham treatment'), males and nests were handled as during a manipulated period. At the average temperatures observed on Culatra (between 20.7 and $24.7^{\circ} \mathrm{C}$, see Ros \& Oliveira, in press), the time estimated from spawning until egg hatching is about 10 days (Fishelson 1963; von Westernhagen 1983), and thus all the eggs that were found in the nests at the beginning of the 2-week period had hatched before the next sampling point. Therefore, these brood size measurements were reliable correlates of the recent spawning activity of females and of the number of eggs received by the males. However, the measurements might somewhat underestimate spawning rate as a consequence of nest-holder males eating some of the eggs in the nest ('filial cannibalism', Manica 2002), which was not quantified in our experiment. A large proportion of nestholders in the peacock blenny have been shown to have some blenniid eggs in their gut (Gonçalves \& Almada 1997). Nest-holders might eat some of the eggs to compensate in part for the loss in condition they suffer from the reduction in foraging opportunity during breeding (Gonçalves \& Almada 1997). Alternatively, they might selectively eat eggs that are diseased and thus nest-holder egg cannibalism could be part of parental care (Almada \& Santos 1995; Kraak 1996). Nevertheless, in the blenniid Aidablennius sphynx, the effect of cannibalism on brood size is negligible for broods larger than about 1000 eggs (Kraak 1996). In the population we studied brood sizes varied between 2000 and 20000 eggs. Even taking into account that $A$. sphynx is a smaller species than the peacock blenny, differences in egg cannibalism between nestholders must have had little effect on the total number of eggs and thus on the outcome of our experiments.

\section{Brood size manipulation}

There is a high level of male-male competition for nest sites on Culatra (Almada et al. 1995). Therefore, extra nesting space is readily accepted. We provided artificial nests (110 transparent PVC tubes (Cristalflex, Heliflex, Gafanha da Encarnação, Portugal) sealed on one side and placed in brick holes) 3 months before the breeding season. Two sizes of tubes were used depending on the available space in the brick (length $15 \mathrm{~cm}$ with a diameter of $31 \mathrm{~mm}$ or $28 \mathrm{~cm}$ with a diameter of $38 \mathrm{~mm}$ ). Tubes were inspected at low tide in the morning hours every other week during the breeding season (average inspection interval $=14.5$ days). Over the whole breeding season a male was found at least once in 85 of these tubes.

At the start of the breeding season we selected 18 males that were site attached and had received clutches of several females in their nest (seen as different egg patches in the tube). From May to the end of July 2006 brood size was estimated from the area of the tube covered with eggs. Additionally, the total length of the occupying nest-holder was measured $( \pm 0.1 \mathrm{~mm})$ at each sampling point. During the first four sampling points in this period, we manipulated brood size by swapping tubes between nest-holders, resulting in three groups: reduced broods (to $35 \pm 8 \%$ of premanipulated brood size, $N=9$ ), sham-treated broods (to $100 \pm 2 \%$ of premanipulated brood size, $N=14$ ) and enlarged broods (to $607 \pm 5 \%$ of premanipulated brood size, $N=11$ ).

To test whether brood size plays a role in female choice, we estimated the effect of brood size manipulation by comparing the brood size after manipulation with the brood size these males had after a sham manipulation. For statistical analysis, this resulted in nine reduced-control pairs and 11 enlarged-control pairs. The order in which animals were treated first, that is, sham, reduced or enlarged, was randomized.

To estimate brood size within the transparent PVC tubes we used the method described by Kraak \& Videler (1991): a sheet of transparent plastic was folded around the tube and the outlines of the areas covered with eggs (deposited in one layer against the wall) were drawn. Sheets were scanned using an Epson flatbed scanner and areas were measured using Adobe Photoshop (accuracy $1 \mathrm{~mm}^{2}$ ). Exact egg counts were made of five broods and by linear regression (without an intercept) the number of eggs per $\mathrm{cm}^{2}$ was calculated. The average number of eggs per $\mathrm{cm}^{2}$ was then used to estimate the number of eggs present in each tube at each sampling point.

Based on previous work (Fagundes et al. 2007) we predicted that female spawning rate in the nest would correlate positively with the size of the nest-holder and with the number of eggs in the nest (see A. sphynx, Kraak \& Videler 1991). From this, we had the following predictions for the manipulation experiment: (1) if brood size is the major determinant of female choice, the enlargement or reduction of brood size through experimental manipulation should correlate positively with spawning rate and thus subsequent brood size (Fig. 1, scenario A); (2) if characteristics of the nest-holder or of the nest are more important determinants for female choice, brood size should return to the control brood size following manipulation (Fig. 1, scenario B).

An alternative explanation for possible effects of brood size manipulation is that males value nests differentially depending on the age of the eggs in the brood (see Magnhagen \& Vestergaard 1993). A post hoc analysis showed that nests with more than about 3500 eggs did not differ significantly in age structure of the eggs, but smaller broods held younger eggs (T. Fagundes, D. Gonçalves \& R.F. Oliveira, unpublished data). Using the relationship between brood size and age resulting from this post hoc analysis, we found that estimated ages of the broods were not significantly different after manipulation between groups (estimated developmental stage (scale 1-3): reduced: $2.01 \pm 0.10$; control: $2.03 \pm 0.06$; enlarged: $2.11 \pm 0.07$; paired $t$ tests: $t<1.84, P>0.20$, Bonferroni corrected). We therefore assumed that differences between broods in the age of the eggs had no systematic effect on our results.

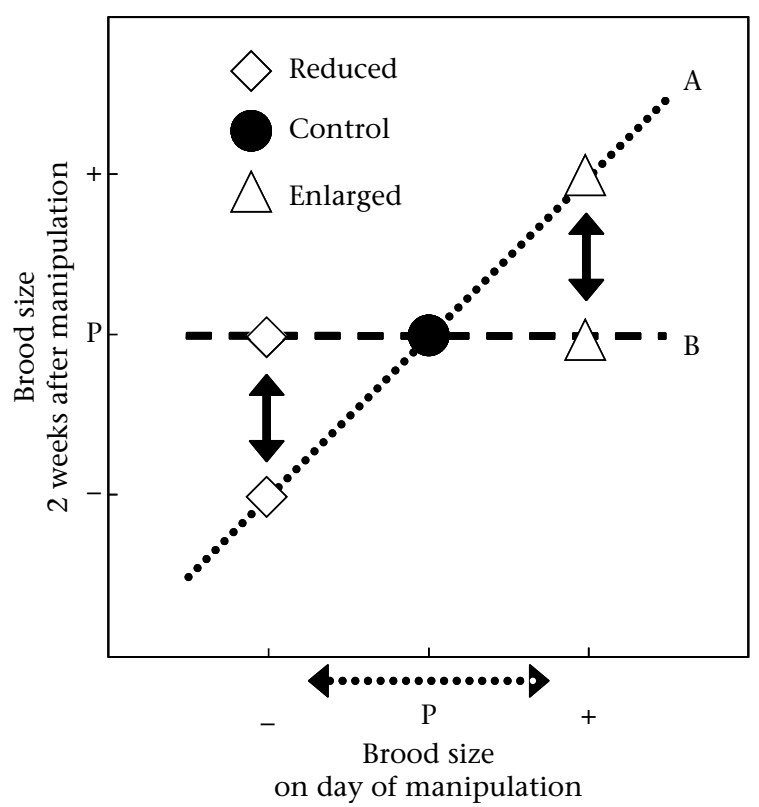

Figure 1. Hypothetical effects of brood size manipulation on subsequent spawning rate. The reduced group received a smaller brood $(-)$ and the enlarged group received a larger brood $(+)$, while the control group remained at premanipulation levels $(P)$. 'Brood size' scenario (A, dotted line): spawning rate is a function of the number of eggs in the nest and brood size will remain at the manipulation level $(-, \mathrm{P},+$ depending on the group); 'male quality' scenario (B, dashed line): spawning rate is independent of the number of eggs in the nest and after manipulation the brood size will return to the premanipulation level $(\mathrm{P})$. 


\section{Measurement of androgen levels}

To measure the relationship between brood size and androgen levels, at the end of the last manipulation period (fourth) and at the end of the subsequent sampling period in which no manipulations of brood size were carried out, all males were captured and a blood sample was drawn. Before blood sampling, fish were anaesthetized using MS-222. Blood was sampled from the caudal vein with a $1 \mathrm{ml}$ heparinized syringe fitted with a 25-gauge needle and placed in $1 \mathrm{ml}$ Eppendorf tubes. Blood was transported on ice to the laboratory, where it was centrifuged at $3000 \mathrm{rpm}$ for $5 \mathrm{~min}$. Plasma was collected and stored at $-20^{\circ} \mathrm{C}$ until radioimmunoassays were carried out. To assess circulating levels of testosterone (T) and 11ketotestosterone (11-KT), the free steroid fraction was extracted from plasma using the methodology described in Scott \& Vermeirssen (1994). Steroid residues were resuspended in $1 \mathrm{ml}$ of assay buffer and stored again at $-20^{\circ} \mathrm{C}$ until assayed for $11-\mathrm{KT}$ and T. For the quantification of $11-\mathrm{KT}$, an antibody donated by D. E. Kime was used and its cross-reactions are described in Kime \& Manning (1982). The antibody for T was purchased from Research Diagnostics (RDI-TRK2T2, Concord, MA, U.S.A.); the cross-reactivities provided by the supplier are $16 \%$ for $5 \alpha$-dihydrotestosterone, $1 \%$ for androstenediol, $0.4 \%$ for androstenione, $<0.1 \%$ for androsterone, $<0.1 \%$ for dehydroepiandrosterone, $<0.1 \%$ for progesterone, $0.001 \%$ for oestradiol and $0.001 \%$ for cortisol/pregnenolone. Intra-assay coefficients of variation for both hormones were $5 \%$ and all samples were analysed within a single assay.

\section{Ethical Note}

In the longitudinal research project, in total 1192 individuals were tagged using a transponder (T. Fagundes, J. Saraiva, D. Gonçalves \& R.F. Oliveira, unpublished data). Only animals above $5.2 \mathrm{~cm}$ total body length were tagged. Surgery was performed only after fish attained a deep state of anaesthesia, as characterized by a total loss of equilibrium and reflexes to stimulation (Summerfelt \& Smith 1990). Fish were allowed to recover from anaesthesia in a small isolation aquarium before they were returned to the site of capture. Research on perch, Perca fluviatilis, has shown that animals of this size do not show severe negative effects of surgical pit tagging (Baras et al. 2000). Of the 1192 marked only eight did not survive this procedure. We could not follow the healing process of the fish after release in the field. However, more than $50 \%$ of the fish were recaptured which is a high recapture percentage for freeliving animals.

For the brood manipulation experiment, males were recognized on external cues and animal handling time was kept to a minimum. All animals survived the experimental procedures. Blood sampling was carried out by a certified researcher (Direcção-Geral de Veterinária) under anaesthesia (see above). In other experiments (e.g. Ros et al. 2004) we found no evident side-effect of blood sampling, and all animals were found in their nests in subsequent visits. The experimental procedures were reviewed by a veterinarian and a licence was granted by the Direcçao Geral de Veterinária, Ministério da Agricultura do Desenvolvimento Rural e Das Pescas. The project was approved by the Fundaçao Para a Ciência e a Technologia.

\section{RESULTS}

\section{Correlates of Brood Size}

The reproductive period started at the end of April and lasted until the end of August, with very few nests in the transect still with eggs at the beginning of September (Fig. 2). During this period on average $13 \pm 1$ nests were found to contain eggs. Estimated total numbers of eggs in the transect (sum of 80 bricks) increased steeply (rate ca. 5000 eggs/day) until reaching stable values in June. After June the estimated total number of eggs slowly declined (rate ca. 2000 eggs/day).

To test the stability of brood size within individual nest-holders, we selected nest-holders that were observed to have eggs in their nest for at least three consecutive periods (Fig. 3). The number of eggs gradually built up during the first three observations after the start of breeding (paired $t$ test: $0 \rightarrow 1$ and $1 \rightarrow 2: t_{79}>4.7$, $P<0.0001 ; P$ values corrected for multiple [5] comparisons with the Bonferroni correction). From the third observation onwards brood size remained stable (paired $t$ tests: $2 \rightarrow 3: t_{47}=0.94$, $P=0.35 ; 3 \rightarrow 4: t_{24}=1.5, P=0.47 ; 4 \rightarrow 5: t_{14}=1.4, P=0.40 ; P$ values corrected for multiple [5] comparisons with the Bonferroni correction; Fig. 3). The average interval between two observations was 18 days and thus all eggs present at the beginning of the interval had hatched before the following measurement of brood size. This effect of previous brood size thus suggests that the number of eggs a nest-holder received was stable over a relatively long period. This stability was not a result of physical limits of the nest because the internal nest area covered by eggs varied widely (range $2-100 \%$, mean $55 \%$ ).

We tested the predictive value of the following characters on brood size in a multiple regression analysis: total length, relative head height (head height/body size), condition factor (weight/body size $^{3}$ ) and previous brood size. Data were selected from the peak of the reproductive period (i.e. the beginning of June). This analysis showed a highly significant effect of both previous brood size and body size $\left(r^{2}=0.57, N=62, P<0.001\right.$; in the regression model: previous brood size: $P<0.001$; body size: $P=0.005$; removed from the model: relative head height, condition, year: $P>0.13$; Fig. 4).

\section{Brood Size Manipulation}

\section{Effects on brood size}

During control periods, brood size of sham-manipulated males correlated positively with body size but not with relative head height (total length: $r_{27}=0.58, P<0.001$; relative head height: $r_{27}=0.16$, NS). Additionally, a strong positive correlation was found for brood size in the first two consecutive sampling points (approximately 2 weeks apart) for the sham-manipulated brood size treatment $\left(r_{16}=0.96, P<0.001\right.$; Fig. 5$)$.

Two weeks after manipulation males with experimentally enlarged broods had larger broods, while males with experimentally reduced broods had smaller broods, than after a sham treatment period (paired $t$ tests: enlarged versus control: $t_{10}=3.67$, $P=0.008$; reduced versus control: $t_{8}=-3.10, P=0.015 ; P$ values corrected for multiple [2] comparisons with the Bonferroni

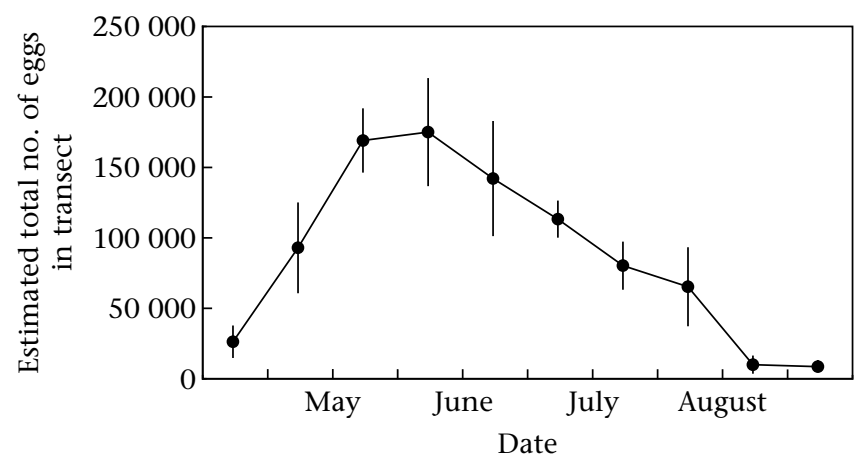

Figure 2. Seasonal variation in total egg number in the studied transect (total number of nests with eggs per season was $23 \pm 2$ ). Means \pm SEM are shown for data collected between 2000 and 2006 . 


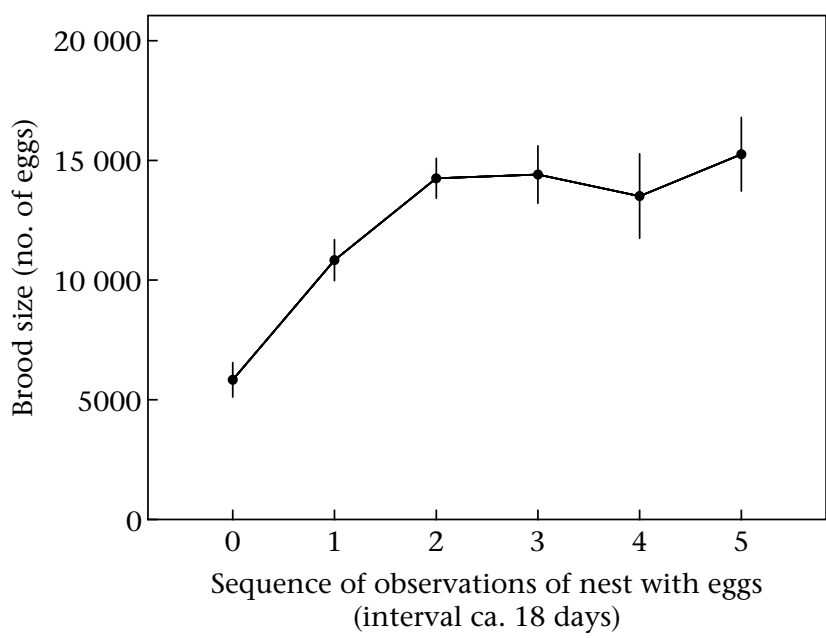

Figure 3. Change in brood size over consecutive sampling intervals (average for all the nests in the transect). Broods were aligned on the first event at which a nest-holder was found to have eggs. Means \pm SEM of individual data are shown.

correction; Fig. 6a). To test whether brood size varied as a function of factors independent of brood size (see Fig. 1, scenario B), we computed residual values of the correlation between manipulated brood size and number of eggs received after the manipulation. To do this, we subtracted brood size values as a consequence of manipulation from the predicted value based on the regression of subsequent brood size on current brood size found in sham-treated nest-holders (Fig. 5). The averages of these residual values were then plotted according to treatment (Fig. 6b). This residual analysis showed that males with enlarged broods had brood sizes as large as expected from their manipulated brood size, while males with reduced broods had significantly larger broods than expected (paired $t$ test: enlarged broods: $t_{10}=-1.02, P=0.3$; reduced broods: $t_{8}=3.37, P=0.020 ; P$ values corrected for multiple [2] comparisons with the Benferroni correction). Thus, although nestholders with reduced broods received fewer eggs (i.e. smaller subsequent broods) than during a control period, they still received significantly more eggs (i.e. larger subsequent broods) than expected from their brood size at manipulation.

\section{Effects on androgen levels}

At the first sampling point, about 2 weeks after manipulation, males had brood sizes that correlated positively with their brood sizes at manipulation (Fig. 7a). However after 1 month broods tended to return to the premanipulation levels (Fig. 7a). These results thus confirm the conclusion of the longitudinal study that spawning is a function of both the number of eggs present in the nest and some character of the nest-holder independent of brood size. The effect of brood size manipulation on the androgen levels was measured in a repeated measures ANCOVA with androgen level at each of the two sampling points as repeated measure and average brood size at these sampling points as covariate. 11-KT levels did not show a significant correlation with brood size $\left(F_{1,13}=0.95, P=0.3\right.$; controls only: $r_{6}=-0.004, P=0.99$; Fig. $\left.7 d\right)$; neither was there a significant effect of brood size manipulation $\left(F_{1,13}=0.06, P=0.8\right.$; Fig. $\left.7 \mathrm{~b}\right)$. In contrast, $\mathrm{T}$ levels showed a significantly positive correlation with brood size $\left(F_{1,13}=6.6, P=0.023\right.$; controls only: $r_{6}=0.86, P=0.007$; Fig. $7 \mathrm{e}$ ) and a significant effect of brood size manipulation $\left(F_{1,13}=5.03, P=0.043\right.$; Fig. $\left.7 \mathrm{c}\right)$. T levels were increased in the reduced group and decreased in the enlarged group (Fig. $7 \mathrm{c})$. They tended to decrease with time $\left(F_{1,13}=3.98\right.$, $P=0.067)$, and similarly to what was found for brood size, 1 month after the manipulation androgen levels did not differ between groups $\left(F_{1,13}=1.71, P=0.21\right.$; Fig. $\left.7 \mathrm{c}\right)$.

\section{DISCUSSION}

In a species with exclusive male parental care, the peacock blenny, a large individual variation was found in brood sizes, which remained relatively stable during the peak of the reproductive period. This reflects consistent variation in female spawning rate, as sampling intervals were longer than hatching time and because, in our sample, brood size was not limited by space for eggs in the nests. Here we discuss possible causal mechanisms by which brood size might be regulated to individual characteristics of nest-holders (for mechanisms by which they might be established see Kraak \& van den Berghe 1992).

\section{Effect of Brood Size Manipulation on Spawning Rate}

We expected that if females base their mate choice only on the number of eggs present in the nests, brood size should remain at manipulation levels (Fig. 1, scenario A). Alternatively, if females spawn independently of the number of eggs in the nest, brood sizes should return to the nonmanipulated brood size (Fig. 1, scenario B). The results showed that, after the first 2 weeks after manipulation, the number of eggs received by the males was clearly predicted by the manipulated brood size. Thus, spawning rate was influenced by brood size. An effect of eggs in the nest on female spawning rate has been shown for several species of teleost fish (Cottus bairdi: Downhower \& Brown 1980; G. aculeatus: Ridley \& Rechten 1981; Cottus gobio: Marconato \& Bisazza 1986; Ethiostoma flabellare: Knapp \& Sargent 1989; Hypsypops rubicundus: Sikkel 1989; Abudefduf luridus: Afonso \& Santos 2005) including a blenny species (A. sphynx, Kraak \& Videler
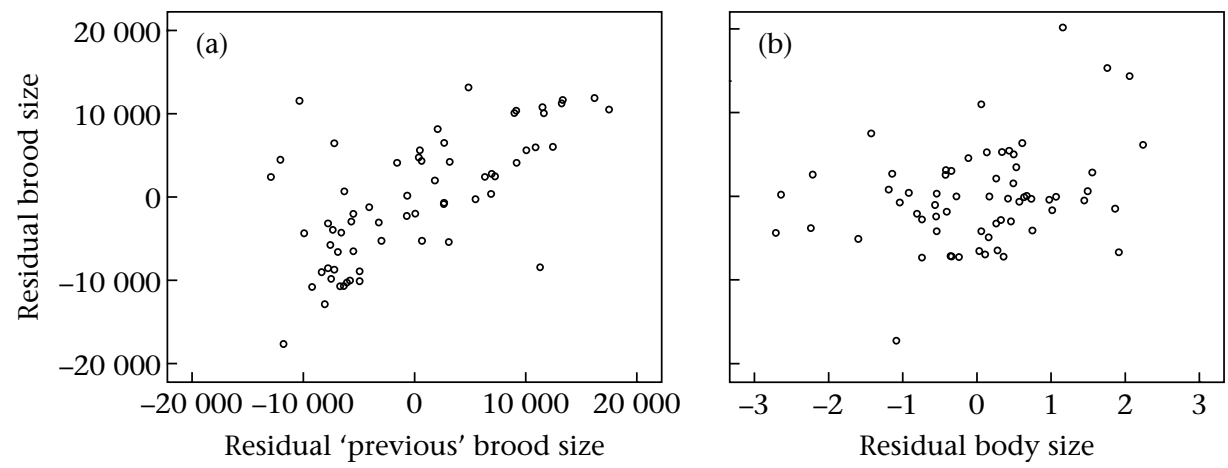

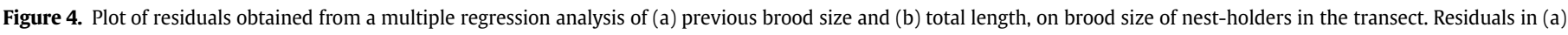
were obtained by partialling out the effect of total length, while residuals in (b) were obtained by partialling out the effect of brood size. 


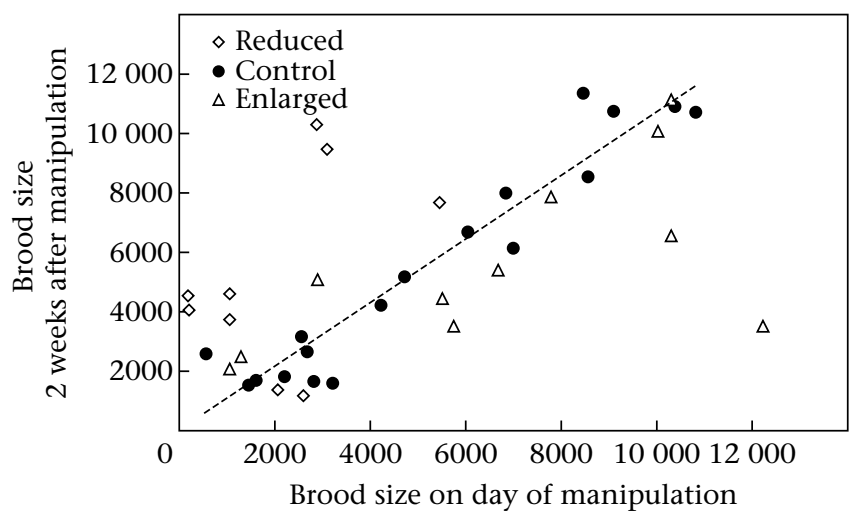

Figure 5. Effect of the brood size manipulation on subsequent spawning rate. Brood sizes on the day of manipulation and 2 weeks later of individual nest-holder males are shown. In a 2-week period all eggs hatch and thus the value on the $Y$ axis can be used as an estimate of the spawning rate after manipulation.

1991). However, 1 month after manipulation brood size returned to premanipulation levels. This return could not be explained by a limited carrying capacity for eggs in a nest, because the effect was found for both reduced and enlarged nests. Thus, both brood sizedependent and brood size-independent effects appeared to play a role in the reproductive success of individual males.

Two mechanisms that are not mutually exclusive may explain the return of brood size to premanipulation levels. (1) Females may

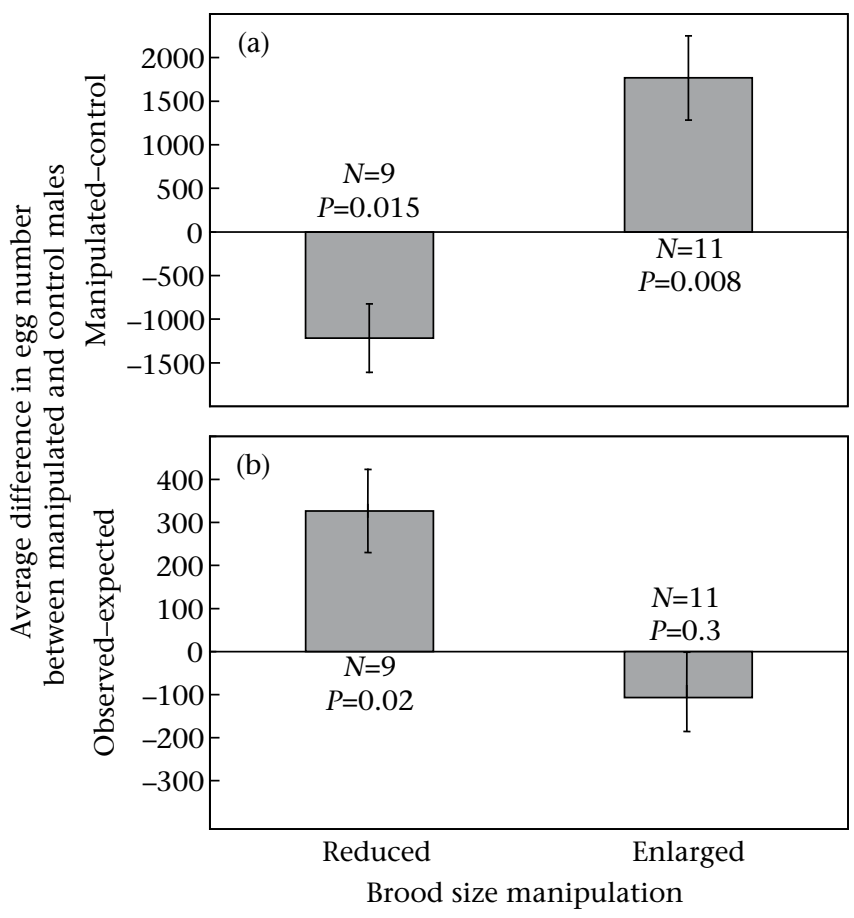

Figure 6. Results of the brood size manipulation experiment. (a) Difference between the number of eggs that a male received after a brood size manipulation and after a control treatment (reduced-control brood size and enlarged-control brood size, respectively). The values reject the hypothesis that spawning rate is associated with 'male quality' only (Fig. 1, scenario B) because this would predict that brood size after manipulation returns to premanipulation (control) levels and thus that values would not differ significantly from zero. (b) Difference between the number of eggs received after manipulation and the number of eggs expected to be received as a function of the brood size attributed by the experimental treatment. The expected values are determined by the linear relationship of Fig. 5 . The values reject the hypothesis that spawning rate is associated with 'brood size' only (Fig. 1, scenario A) because this would predict that values would not differ significantly from zero. Means $\pm S E M$ are shown. choose characteristics of the male that are independent of brood size variation. Such characteristics might be secondary sexual characters or male body size (Fagundes et al. 2007; this study). (2) Males may adjust brood size to some individually set value. Males may do so through modulation of female spawning rate via sexual and agonistic behaviours and through filial cannibalism (Manica 2002). Functionally, this may optimize their current and future reproductive effort, because care and defence behaviours are costly activities (van den Berghe 1992; Almada et al. 1994; Gonçalves \& Almada 1997, 1998; Cooke et al. 2006) and parental effort has been found to be proportional to brood size in several fish species (e.g. Magnhagen \& Vestergaard 1993; Karino \& Arai 2006). Brood size might also drop to a level at which the expected fitness benefit of raising that brood becomes lower than the expected loss of future reproduction as a consequence of the parental effort necessary to do so. For example, parental males of several fish species that received a small brood have been observed to cannibalize or abandon this brood and start to attract new females (Taborsky 1985; Smith \& Wootton 1995; Balshine-Earn \& Earn 1998).

In accordance with our study, two other studies on blennies have reported that female spawning is positively correlated with brood size (peacock blenny: Fagundes et al. 2007; A. sphynx: Kraak \& Videler 1991). Kraak \& Groothuis (1994) tested in A. sphynx whether female choice for large brood size was a direct stimulatory effect of the number of eggs in the nest, or a consequence of choosiness for some feature in male courtship. In a series of choice tests they did not detect obvious differences in the behaviour of males of $A$. sphynx that were holding a nest with many or few eggs, a result that has also been found in an experimental study in the sand goby, Pomatoschistus minutus (Nyman et al. 2006). Moreover, based on visual cues from the males alone, females of $A$. sphynx choose randomly in respect to the number of eggs in the nest for their first approach. When subsequently females were allowed to inspect both nests they showed the expected preference for spawning in nests with many eggs. Thus, female inspection of the number of eggs in the nest plays an important role in female spawning and affects the resulting brood size. Still, Kraak \& Groothuis (1994) did not rule out the possibility that male courtship display and characteristics (Fig. 1, scenario B) might play a role in a different context, for example to attract females to the nest.

In accordance with the data on A. sphynx, field observations in the peacock blenny have shown that fecund females inspect several nests before they spawn (Fagundes et al. 2007). These females sometimes return to a nest they have already inspected suggesting that females do compare some feature of quality between males or their nests. Indeed, females spawned with relatively larger males, with a larger head crest, anal gland and genital papilla, that had more eggs in their nests and that courted the female (Fagundes et al. 2007). Here we have confirmed that brood size plays a role in this choice process, since males with experimentally enlarged broods received more eggs than in a control situation while males with experimentally reduced broods received relatively fewer eggs.

\section{Androgen Levels and Variation in Brood Size}

Based on comparative data for a wide range of vertebrate species a trade-off has been proposed between parental behaviour and androgen levels (reviewed in Ziegler 2000; Hirschenhauser \& Oliveira 2006). For example in birds, T facilitates behaviours that play a role in sexual competition. The energetic and time requirements of such androgen-dependent mating and fighting behaviours are mostly incompatible with providing protection and food for young (Wingfield et al. 1990). Therefore we expected to find a negative relationship between the number of eggs in the nest (cared for by the male) and androgen levels. This effect should be found especially in 

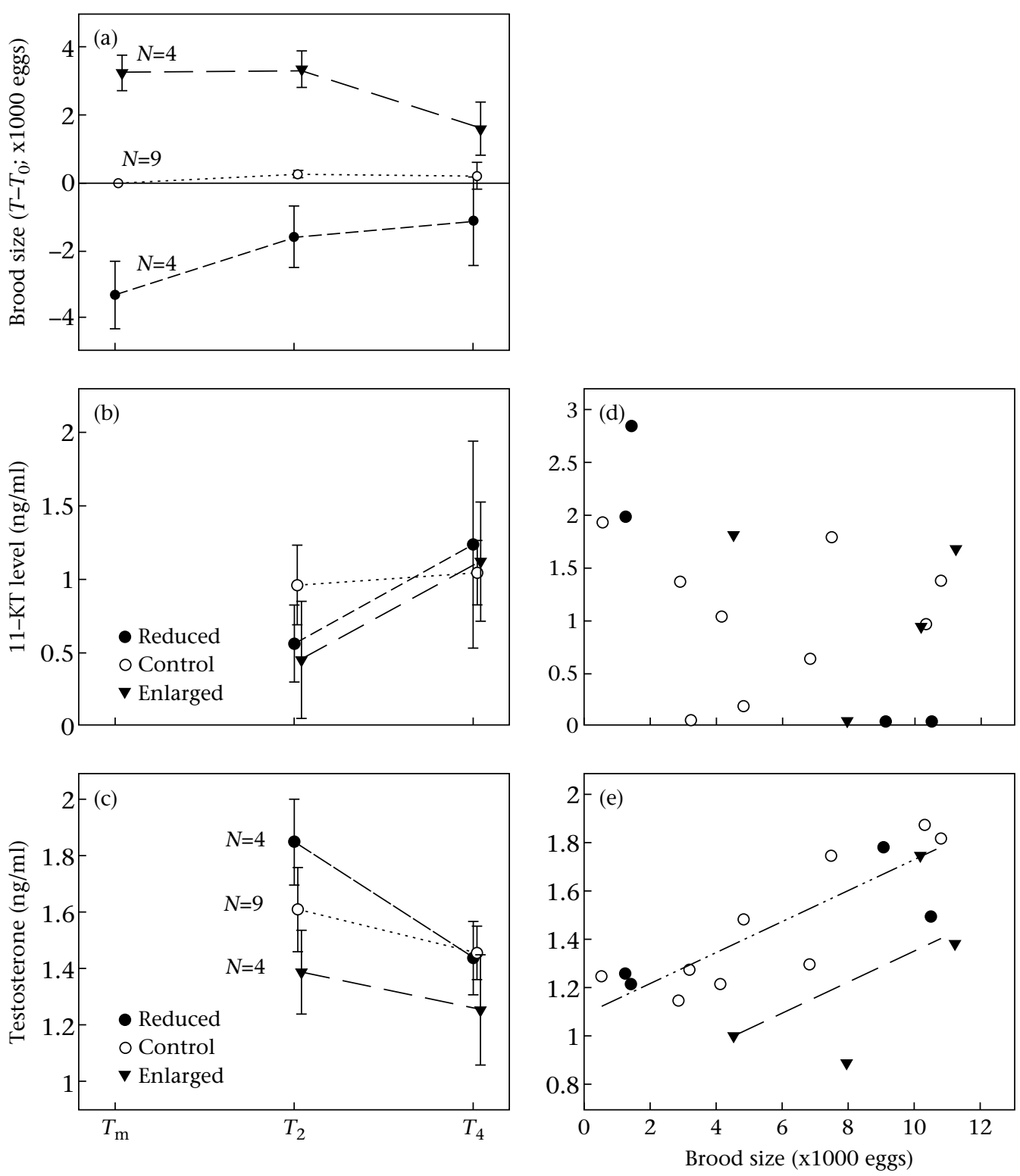

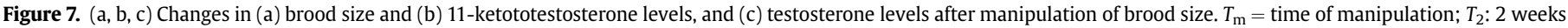

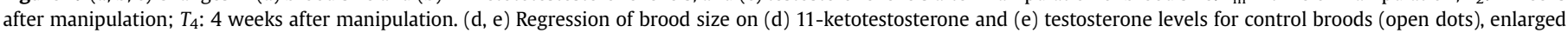
broods (closed triangles) and reduced broods (closed dots).

the androgen 11-KT because this is the major biologically active androgen in male teleosts (Kime 1993; Borg 1994). Contrary to this expectation, we did not find evidence for such a negative relationship between 11-KT levels and brood size, either correlative or as a result of experimental manipulation of brood size. Recently, several experimental studies have suggested that 11-KT does not 'trade-off' with parental care in fish (e.g. Trichogaster trichopterus: Kramer 1972; Parablennius parvicornis: Ros et al. 2004; Lythrypnus dalli: Rodgers et al. 2006). The lack of a negative relationship between 11-KT and parental care might be explained by the fact that male competitive behaviours and parental care are not mutually exclusive in fish. In many species of fish males care for several overlapping clutches and mating and parental care behaviours are often carried out in the nest territory (Smith \& Wootton 1995).

In contrast to 11-KT, T showed a positive curvilinear relationship with brood size. Since males that have more eggs in their nests are expected to participate in more spawning episodes with females, this might explain the positive relationship between plasma levels of $\mathrm{T}$ and brood size. In adult males that compete within the conventional male reproductive context, that is, are exposed to male-male competition and female choice, exposure to fecund females appears to induce the production of gonadotrophins and the growth of the testes (Kobayashi et al. 2002). Social experience is also known to affect the activity of steroidogenic enzymes involved in androgen metabolism in fish, namely aromatase, which converts T into oestradiol, and 11-beta-HSD which metabolizes T into 11-KT (Leitz 1987; Frisch 2004). Therefore, it is possible that these biochemical switches (i.e. aromatase and 11-beta-HSD) are differentially activated by mating experience, resulting in a decoupling of the social effects on the two measured androgens (T and 11-KT). For example, in Sarotherodon galilaeus, a tilapia with both male and female mouthbrooding, $\mathrm{T}$ levels increased and 11-KT levels decreased in reproductively active males that were in a femalebiased operational sex ratio group in comparison to males in a male-biased group (Ros et al. 2003). Males in such female-biased groups had higher spawning rates than those in male-biased 
groups and also showed higher gonadosomatic indexes suggesting again a positive relationship between testis size and $\mathrm{T}$ production.

The temporary reduction in $\mathrm{T}$ following brood size enlargement and its rise following a reduction in brood size, support a 'trade-off' between $\mathrm{T}$ and parental investment since larger broods require more parental care. The positive relationship between $\mathrm{T}$ and brood size discussed above does not necessarily contradict the existence of this trade-off since good-quality males may support the costs of higher levels of $\mathrm{T}$ while performing parental care. The changes in $\mathrm{T}$ levels might explain the consistency of individual male brood size found in this species, since spawning rate after manipulation mirrored changes in T levels. Although not studied so far for the peacock blenny, $\mathrm{T}$ might facilitate oestradiol-dependent sexual displays and thereby spawning rate. In guppies, aromatization of $\mathrm{T}$ to oestradiol affects two out of three of the investigated male sexual displays (Hallgren et al. 2006). Therefore, the changes in T levels as a result of brood size manipulation found in the peacock blenny make it worth considering that nest-holders actively maintain the number of eggs in their nest.

Two other studies on teleosts have measured the effect of brood size manipulation on androgen levels. In $L$. macrochirus control broods were compared with broods from which half of the eggs were removed experimentally. In males with these reduced broods both T and 11-KT levels increased (Magee \& Neff 2006). In G. aculeatus brood size was manipulated by allowing three, one or no females to spawn in a nest. Males with three females showed a stronger decline in 11-KT levels than males with only one female, while 11-KT levels in males that had no brood in their nest remained elevated. T levels were not measured in this study (Páll et al. 2002a). Thus both studies show an effect of brood size manipulation on androgen levels as we have shown in the peacock blenny. However, in contrast to the peacock blenny, L. macrochirus and G. aculeatus 11-KT responded to the manipulation. There is too little knowledge on the effect of the different androgens on the breeding behaviour of the different species to explain this partial difference in results.

In conclusion, the available evidence suggest that brood sizes in the peacock blenny are associated with quality characteristics of individual nest-holders. Experimental manipulation of brood size resulted in a correlated change in spawning rate but this effect was only temporary suggesting that brood size is regulated to an individually set value. Both female choice and male sexual and aggressive behaviour might play a role in maintaining this value. Changes in androgen levels ( $\mathrm{T}$ in this study) in response to changes in brood size might assist in individual regulation of brood size because androgens facilitate sexual competitive behaviours. The function of such a mechanism might be to optimize brood size to the quality of the male given its social environment.

\section{Acknowledgments}

The experiment and manuscript benefitted greatly from discussions with the IBBG group of ISPA, Redouan Bshary and Miguel Taborsky, and two anonymous referees. We also express our gratitude to Tânia Oliveira for professional assistance during radioimmunoassays and Dr. D. E. Kime, University of Sheffield, U.K. for the donation of 11-ketotestosterone antibody. The direction of the Parque Natural da Ria Formosa provided essential technical and logistical support. The study was conducted under the research grant POCTI/BSE/38395/2001 and the research of R.F.O and A.F.H.R. was supported by the Plurianual Program of the Portuguese Foundation for Science and Technology (FCT) (R\&D Unit 331/94). T.F. and A.F.H.R were supported by FCT PhD grant SFRH/BD/6502/ 2001 and postdoc grant SFRH/BPD/7143/2001, respectively.

\section{References}

Afonso, P. \& Santos, R. S. 2005. Within-nest spawning-site preferences of female bluefin damselfish: the effect of early stage eggs. Acta Ethologica, 8, 5-11.

Almada, V. C. \& Santos, R. S. 1995. Parental care in the rocky intertidal: a case study of adaptation and exaptation in Mediterranean and Atlantic blennies. Reviews in Fish Biology and Fisheries, 5, 23-37.

Almada, V. C., Gonçalves, E. J., Santos, A. J. \& Baptista, C. 1994. Breeding ecology and nest aggregations in a population of Salaria pavo (Pisces: Blenniidae) in an area where nest sites are very scare. Journal of Fish Biology, 45, 819-830.

Almada, V. C., Gonçalves, E. J., Oliveira, R. F. \& Santos, A. J. 1995. Courting females: ecological constraints affect sex roles in a natural population of the blenniid fish Salaria pavo. Animal Behaviour, 49, 1125-1127.

Balshine-Earn, S. \& Earn, D. J. D. 1998. On the evolutionary pathway of parental care in mouth-brooding cichlid fish. Proceedings of the Royal Society of London, Series B, 265, 2217-2222.

Baras, E., Malbrouck, C., Houbart, M., Kestemont, P. \& Mélard, C. 2000. The effect of PIT tags on growth and physiology of age-0 cultured Eurasian perch Perca fluviatilis of variable size. Aquaculture, 185, 159-173.

van den Berghe, E. P. 1992. Parental care and the cost of reproduction in a Mediterranean fish. Behavioral Ecology and Sociobiology, 30, 373-378.

Borg, B. 1994. Androgens in teleost fishes. Comparative Biochemistry and Physiology, 109C, 219-245.

Carlisle, T. R. 1982. Brood success in variable environments: implications for parental care allocation. Animal Behaviour, 30, 824-836.

Clutton-Brock, T. H. 1991. The Evolution of Parental Care. Princeton, New Jersey: Princeton University Press.

Coleman, R. M., Gross, M. R. \& Sargent, R. C. 1985. Parental investment decision rules: a test in bluegill sunfish. Behavioral Ecology and Sociobiology, 18, 59-66.

Cooke, S. J., Philipp, D. P., Wahl, D. H. \& Weatherhead, P. J. 2006. Energetics of parental care in six syntopic centrarchid fishes. Oecologia, 148, 235-249.

Deerenberg, C. \& Overkamp, G. J. 1999. Hard work impinges on fitness: an experimental study with zebra finches. Animal Behaviour, 58, 173-179.

Downhower, J. F. \& Brown, L. 1980. Mate preferences of female mottled sculpins. Animal Behaviour, 28, 728-734.

Fagundes, T., Gonçalves, D. M. \& Oliveira, R. F. 2007. Female mate choice and mate search tactics in a sex role reversed population of the peacock blenny, Salaria pavo (Risso, 1810). Journal of Fish Biology, 71, 77-89.

Fishelson, L. 1963. Observations on littoral fishes of Israel II. Larval development and metamorphosis of Blennius pavo Risso (Teleostei, Blenniidae). Israel Journa of Zoology, 12, 81-91.

Frisch, A. 2004. Sex-change and gonadal steroids in sequentially-hermaphroditic teleost fish. Reviews in Fish Biology and Fisheries, 14, 481-499.

Gonçalves, E. J. \& Almada, V. C. 1997. Sex differences in resource utilization by the peacock blenny. Journal of Fish Biology, 51, 624-633.

Gonçalves, E. J. \& Almada, V. C. 1998. A comparative study of territoriality in intertidal and subtidal blennioids (Teleostei, Blennioidei). Environmental Biology of Fishes, 51, 257-264.

Gonçalves, D. M., Simoes, P. C., Chumbinho, A. C., Correia, M. J., Fagundes, T. \& Oliveira, R. F. 2002. Fluctuating asymmetries and reproductive success in the peacock blenny. Journal of Fish Biology, 60, 810-820.

Gonçalves, D., Fagundes, T. \& Oliveira, R. 2003. Reproductive behaviour of sneaker males of the peacock blenny. Journal of Fish Biology, 63, 528-532.

Hallgren, S. L., Linderoth, M. \& Olsen, K. H. 2006. Inhibition of cytochrome p450 brain aromatase reduces two male specific sexual behaviours in the male Endler guppy (Poecilia reticulata). General and Comparative Endocrinology, 147, 323-328.

Hirschenhauser, H. \& Oliveira, R. F. 2006. Social modulation of androgens in male vertebrates: meta-analyses of the challenge hypothesis. Animal Behaviour, 71 265-277.

Karino, K. \& Arai, R. 2006. Effect of clutch size on male egg-fanning behavior and hatching success in the goby, Eviota prasina (Klunzinger). Journal of Experimental Marine Biology and Ecology, 334, 43-50.

Ketterson, E. D., Nolan, V., Cawthorn, M. J., Parker, P. G. \& Ziegenfus, C. 1996 Phenotypic engineering: using hormones to explore the mechanistic and functional bases of phenotypic variation in nature. Ibis, 138, 70-86.

Kime, D. 1993. 'Classical' and 'non-classical' reproductive steroids in fish. Reviews in Fish Biology and Fisheries, 3, 160-180.

Kime, D. E. \& Manning, N. J. 1982. Seasonal patterns of free and conjugated androgens in the brown trout Salmo trutta. General and Comparative Endocrinology, 48, 222-231.

Kindler, P. M., Bahr, J. M. \& Philipp, D. P. 1991. The effects of exogenous 11-ketotestosterone, testosterone, and cyproterone acetate on prespawning and parental care behaviors of male bluegill. Hormones and Behavior, 25, 410-423.

Knapp, R. A. \& Sargent, R. C. 1989. Egg mimicry as a mating strategy in the fantail darter, Ethiostoma flabellare, females prefer males with eggs. Behavioral Ecology and Sociobiology, 25, 321-326.

Kobayashi, M., Sorensen, P. W. \& Stacey, N. E. 2002. Hormonal and pheromona control of spawning behavior in the goldfish. Fish Physiology and Biochemistry 26, 71-84.

Kraak, S. B. M. 1996. Female preference and filial cannibalism in Aidablennius sphynx (Teleostei, Blenniidae); a combined field and laboratory study. Behavioural Processes, 36, 85-97. 
Kraak, S. B. M. \& van den Berghe, E. P. 1992. Do female fish assess paternal quality by means of test eggs? Animal Behaviour, 43, 865-867.

Kraak, S. B. M. \& Groothuis, T. G. G. 1994. Female preference for nests with eggs is based on the presence of the eggs themselves. Behaviour, 131, 189-206.

Kraak, S. B. M. \& Videler, J. 1991. Mate choice in Aidablennius sphynx (Teleostei, Blenniidae); females prefer nests containing more eggs. Behaviour 119, 243-266.

Kramer, D. L. 1972. The role of androgens in the parental behaviour of the blue gourami, Trichogaster trichopterus (Pisces, Belontiidae). Animal Behaviour, 20, 798-807.

Leitz, T. 1987. Social control of testicular steroidogenic capacities in the Siamese fighting fish Betta splendens Regan. Journal of Experimental Zoology, 244, 473-478.

Lessells, C. M. 1993. The cost of reproduction: do experimental manipulations measure the edge of the options set? Etologia, 3, 95-111.

Magee, S. E. \& Neff, B. D. 2006. Temporal variation in decisions about parental care in bluegill, Lepomis macrochirus. Ethology, 112, 1000-1007.

Magnhagen, C. \& Vestergaard, K. 1993. Brood size and offspring age affect risk taking and aggression in nest-guarding common gobies. Behaviour, 125, 233-243.

Manica, A. 2002. Filial cannibalism in teleost fish. Biological Reviews, 77, 261-277.

Marconato, A. \& Bisazza, A. 1986. Males whose nests contain eggs are preferred by female Cottus gobio L. (Pisces, Cottidae). Animal Behaviour, 34, 1580-1582.

Murphy, C. A. \& Stacey, N. E. 2002. Methyl-testosterone induces male-typical ventilatory behavior in response to putative steroidal pheromones in female round gobies (Neogobius melanostomus). Hormones and Behaviour, 42, 109-115.

Nyman, A., Kvarnemo, C. \& Svensson, 0. 2006. The capacity for additional matings does not affect male mating competition in the sand goby. Animal Behaviour, 71 865-870.

Oliveira, R. F. 2005. Hormones, social context and animal communication. In: Animal Communication Networks (Ed. by P. K. McGregor), pp. 481-520. Cambridge: Cambridge University Press.

Oliveira, R. F., Almada, V. C., Forsgren, E. \& Gonçalves, E. J. 1999. Temporal variation in male traits, nesting aggregations and mating success in the peacock blenny, Salaria pavo. Journal of Fish Biology, 54, 499-512.

Oliveira, R. F., Miranda, J. A., Carvalho, N., Gonçalves, E. J., Grober, M. S. \& Santos, R. S. 2000. Male mating success in the Azorean rock-pool blenny: the effects of body size, male behaviour and nest characteristics. Journal of Fish Biology, 57, 1416-1428.

Oliveira, R. F., Carvalho, N., Miranda, J., Gonçalves, E. J., Grober, M. \& Santos, R. S. 2002. The relationship between the presence of satellite males and nestholders' mating success in the Azorean rock-pool blenny Parablennius sanguinolentus parvicornis. Ethology, 108, 223-235.

Páll, M. K., Mayer, I. \& Borg, B. 2002a. Androgen and behavior in the male threespined stickleback, Gasterosteus aculeatus I. Changes in 11-ketotestosterone levels during the nesting cycle. Hormones and Behavior, 41, 377-383.

Páll, M. K., Mayer, I. \& Borg, B. 2002b. Androgen and behavior in the male three-spined stickleback, Gasterosteus aculeatus. II. Castration and 11-ketoandrostenedione effects on courtship and parental care during the nesting cycle. Hormones and Behavior, 42, 337-344.
Ridley, M. \& Rechten, C. 1981. Female sticklebacks prefer to spawn with males whose nests contain eggs. Behaviour, 76, 152-161.

Ros, A. F. H., Canário, A. V. M., Couto, E., Zeilstra, I. \& Oliveira, R. F. 2003. Endocrine correlates of intra-specific variation in the mating system of the St. Peter's fish (Sarotherodon galilaeus). Hormones and Behavior, 44, 365-373.

Ros, A. F. H., Bruintjes, R., Santos, R. S., Canário, A. V. M. \& Oliveira, R. F. 2004. The role of androgens in the trade-off between territorial and parental behavior in the Azorean rock-pool blenny, Parablennius parvicornis. Hormones and Behavior, 46, 491-497.

Ros, A. F. H. \& Oliveira, R. F. In Press. Androgens and immune function in male alternative reproductive morphotypes of the peacock blenny Salaria pavo. Ethology.

Rodgers, E. W., Earley, R. L. \& Grober, M. S. 2006. Elevated 11-ketotestosterone during paternal behavior in the bluebanded goby (Lythrypnus dalli). Hormones and Behavior, 5, 610-614.

Sargent, R. C. \& Gross, M. R. 1986. William's principle: an explanation of parental care in teleost fishes. In: The Behaviour of Teleost Fishes (Ed. by T. Pitcher), pp. 275-293. London: Croom Helm.

Scott, A. P. \& Vermeirssen, E. L. M. 1994. Production of conjugated steroids by teleost gonads and their role as pheromones. In: Perspectives in Comparative Endocrinology (Ed. by K. G. Davey, R. E. Peter \& S. S. Tobe), pp. 645-654. Ottawa: National Research Council of Canada.

Sikkel, P. C. 1989. Egg presence and developmental stage influence spawning-site choice by female garibaldi. Animal Behaviour, 38, 447-456.

Smith, C. \& Wootton, R. J. 1995. The costs of parental care in teleost fishes. Reviews in Fish Biology and Fisheries, 5, 7-22.

Stearns, S. C. 1992. The Evolution of Life Histories. Oxford: Oxford University Press.

Summerfelt, R. C. \& Smith, L. S. 1990. Anesthesia, surgery, and related techniques. In: Methods for Fishery Biology (Ed. by C. B Schreck \& P. B. Moyle), pp. 213-272. Bethesda, Maryland: American Fisheries Society.

Taborsky, M. 1985. On optimal parental care. Zeitschrift für Tierpsychologie, 70, 331-336.

Trivers, R. L. 1972. Parental investment and sexual selection. In: Sexual Selection and the Descent of Man (Ed. by B. Campbell), pp. 136-179. Chicago: Aldine.

Vélez, M. J., Jennions, M. D. \& Telford, S. R. 2002. The effect of an experimental brood reduction on male desertion in the Panamanian blue acara cichlid Aequidens coeruleopunctatus. Ethology, 108, 331-340.

von Westernhagen, H. 1983. Observations on the reproductive and larval biology of Blennius pavo (Pisces: Teleostei). Helgolander Meeresuntersuchungen, 36 323-335.

Williams, G. C. 1966. Natural selection, the costs of reproduction, and a refinement of Lack's principle. American Naturalist, 100, 687-690.

Wingfield, J. C., Hegner, R. E., Dufty, A. M. \& Ball, G. F. 1990. The "challenge hypothesis': theoretical implications for patterns of testosterone secretion, mating systems, and breeding strategies. American Naturalist, 136, 829-846.

Ziegler, T. E. 2000. Hormones associated with non-maternal infant care: a review of mammalian and avian studies. Folia Primatologica, 71, 6-21. 